\title{
Cardiovascular Disease Risk Factors and Health Outcomes Among American Indians in Oklahoma: the THRIVE Study
}

\author{
Valarie Blue Bird Jernigan ${ }^{1} \cdot$ Marianna Wetherill $^{1} \cdot$ Jordan Hearod $^{1} \cdot$ Tvli Jacob $^{1}$ • \\ Alicia L. Salvatore ${ }^{1}$ - Tamela Cannady ${ }^{2}$ Mandy Grammar $^{2}$ • Joy Standridge ${ }^{3}$. \\ Jill Fox $^{3} \cdot$ Jennifer Spiegel $^{3}$ - AnDina Wiley ${ }^{3} \cdot$ Carolyn Noonan $^{4} \cdot$ Dedra Buchwald $^{4}$
}

Received: 14 September 2016 / Revised: 9 November 2016/Accepted: 11 November 2016/Published online: 6 December 2016

(C) The Author(s) 2016. This article is published with open access at Springerlink.com

\begin{abstract}
Introduction Limited available data document higher prevalences of cardiovascular disease (CVD) risk factors and health outcomes among American Indians (AIs) compared to other racial/ethnic groups.

Methods As part of a randomized control trial to improve tribal food and physical activity environments, our tribalacademic partnership surveyed a cross-sectional sample of American Indian adults $(n=513)$ to assess the prevalence of type 2 diabetes, obesity, hypertension, tobacco use, physical activity, and vegetable and fruit intake. Surveys were collected from April through May 2015. We used logistic regression to examine the association between CVD-related risk factors and health outcomes.

Results The prevalence of CVD-related outcomes was high, ranging from $25 \%$ for diabetes to $75 \%$ for low vegetable intake. The prevalence of diabetes, obesity, and hypertension tended to be higher among participants with any tobacco use compared to no tobacco use, but findings were not statistically significant. The prevalence of diabetes (prevalence ratio $2.1,95 \%$ CI 1.4-3.2) and obesity (prevalence ratio 1.5,
\end{abstract}

Valarie Blue Bird Jernigan

Valarie-Jernigan@ouhsc.edu

1 College of Public Health, University of Oklahoma Health Sciences Center, 4502 E 41st St., Tulsa, OK 74105, USA

2 Choctaw Nation of Oklahoma Health Services Authority, One Choctaw Way, Talihina, OK 74571, USA

3 Chickasaw Nation Nutrition Services Department, 518 E. Arlington, Ada, OK 74820, USA

4 Initiative for Research and Education to Advance Community Health (IREACH), Washington State University, 1100 Olive Way, Suite 1200, Seattle, WA 98101, USA
95\% CI 1.2-1.8) was higher among participants with low physical activity levels compared to recommended physical activity levels. Conclusions CVD risk factors and health outcomes persist among American Indians even as some risks (e.g., smoking) appear to be stabilizing or even declining in the general US population. Efforts to include American Indians in national health surveys, implement broad reaching environmental and policy interventions, and address the social determinants of health are critical to the elimination of these disparities.

Keywords American Indian · Native American . Cardiovascular disease $\cdot$ Diabetes $\cdot$ Obesity $\cdot$ Vegetable and fruit intake $\cdot$ Community-based participatory research

\section{Introduction}

Although data for American Indian (AI) populations are more limited than for other populations, available data indicate significant and widening disparities in cardiovascular disease (CVD) risk factors such as tobacco use, physical activity, vegetable and fruit intake, health outcomes such as type 2 diabetes, obesity, and hypertension. Our analysis of Behavioral Risk Factor Surveillance Survey (BRFSS) data, one of only a few national health surveys that collects data on AIs, found that from 1996 to 2006, the adjusted prevalence of obesity among AI adults increased by one quarter, from 25 to $31 \%$, while diabetes increased by $27 \%$, from 6.7 to $8.5 \%$ [1]. Hypertension increased by $5 \%$, from 28.1 to $29.5 \%$ [1]. During the same time period, we found no meaningful improvements in smoking behaviors, physical activity, or fruit or vegetable intake [1].

In Oklahoma, currently ranked 45th in the nation with regard to its health outcomes [2], BRFSS data reveal that adult AIs are even more likely than whites to be obese (42 vs. $31 \%$ ) and to have diabetes (15 vs. $10 \%$ ) [3]. More than $60 \%$ of AI 
youth in Oklahoma are overweight [4], and 22\% are obese [5], even though AI youths are at least as concerned about their weight as non-Hispanic whites [6]. Food insecurity, the limited or uncertain availability of healthy foods, a condition highly associated with obesity, diabetes, and hypertension [7], is three times more common among AIs than whites (21.3 vs. $7.3 \%$, respectively) [8]. Finally, less than half of AI adults in Oklahoma meet current physical activity guidelines [9].

Tribal nations have implemented a number of programs to prevent and address CVD and diabetes, primarily by offering health education to individual patients within tribal clinic and Indian Health Service settings. Few, if any, of these programs have intervened broadly at environmental or policy levels [10]. Reasons for the lack of environmental and policy interventions vary but include limited AI health outcomes data [11, 12], which hinders tribal leaders in developing effective health policies. Additionally, public databases that catalog and monitor federal and state policies do not include the policies of sovereign tribal nations within these databases [13, 14]; thus, health planners and researchers remain unfamiliar with tribal policies as well as tribal policymaking processes. In terms of environmental interventions, most evidence-based environmental interventions, such as the implementation of sidewalks and streetlights to promote physical activity or healthy retail corner store strategies to promote healthy eating, have been designed primary for urban settings, with few or none having been tailored to and evaluated in sovereign tribal lands.

The Tribal Health and Resilience in Vulnerable Environments or "THRIVE" study is a community-based participatory research (CBPR) study aimed at improving the food environments within the Chickasaw Nation and the Choctaw Nation of Oklahoma. To inform the development of appropriate interventions in each of these nations, our tribal and academic partners collaboratively developed and conducted several studies: (1) a cross-sectional survey of food and activity environments, health behaviors, and health outcomes, (2) a health impact assessment, and (3) qualitative research with tribal convenience store employees and patrons. Here, we present data from the first of these studies to analyze the prevalence and associations between selected CVD risk factors (i.e., tobacco use, physical activity, and vegetable and fruit intake) and health outcomes (type 2 diabetes, obesity, and hypertension) for the two nations. Study findings were used to identify and prioritize evidencebased community-driven, multilevel intervention strategies to improve health and well-being in both tribal nations.

\section{Methods}

\section{Study Orientation and Partnership}

A CBPR orientation guided all aspects of this study. Our tribaluniversity partnership was comprised of university researchers with prior experience conducting CBPR and key stakeholders from both nations who represented a range of tribal service sectors, including health promotion, nutritional and clinical services, and tribal Institutional Review Boards (IRB) and research divisions. The development of our partnership processes and study methods was informed by partners' previous CBPR with tribes in Oklahoma and elsewhere [15]. A steering committee, comprised of 15 partners, met in person monthly or more often throughout the study at tribal facilities. To inform the development of this baseline survey, the study PI, a tribal citizen, and the lead author of this manuscript presented key questions from national health surveys, such as BRFSS as well as surveys from studies conducted with other AI communities. Survey questions were discussed and selected based on existing standardized questionnaires, modified slightly in language, to be implemented within these tribal communities. This study was reviewed and approved by the Institutional Review Boards of the University of Oklahoma as well as the Chickasaw Nation and Choctaw Nation of Oklahoma. Per the preferences of the tribal partners tribal identity are not included when presenting specific survey results.

\section{Setting}

The Chickasaw Nation and the Choctaw Nation of Oklahoma, both located in the southeastern portion of Oklahoma, are similar in size, population, and rurality. The Chickasaw Nation occupies $7270 \mathrm{mile}^{2}(\sim 10 \%$ of the area of Oklahoma), with a total population of 277,416 , of whom $32,312(12 \%)$ are AI [16]. The Choctaw Nation of Oklahoma occupies 10,602 mile $^{2}(\sim 15 \%$ of the area of Oklahoma), with a total population of 224,472 , of whom $39,984(18 \%)$ are AI. These tribal nations, once reservations, are now classified as Tribal Jurisdictional Areas by the US government. Poverty rates for all residents of the Chickasaw Nation $(15.3 \%)$ and the Choctaw Nation of Oklahoma $(20.7 \%)$ exceed the national poverty rate (13.8\%) [16].

\section{Study Recruitment and Data Collection}

Potential study participants were recruited and screened for eligibility by trained tribal staff in community locations selected by tribal research partners. These locations included tribal community centers, health clinics, tribal convenience stores, health fairs, and at community events including tribal cultural fairs and festivals. To be eligible, participants had to be at least 18 years old, live within the jurisdictional areas of the two tribal nations, and self-identify as American Indian or Alaskan Native. Participants elected whether they wanted to complete a paper survey or an electronic survey via an iPad. All participants completed informed consent prior to beginning the survey and were mailed a $\$ 30$ gift card afterward. A total of $513 \mathrm{AI}$ adults completed the survey between April and May of 2015 with a survey response of $91.4 \%$. 


\section{Measures}

Health Outcomes We assessed diabetes and hypertension by asking "Have you ever been told by a doctor, nurse, or other health professional that you have diabetes/high blood pressure?" Response options included Yes, Yes but I am female and was told only during pregnancy, No, and told that I was borderline diabetic/pre-hypertensive. Only "Yes" responses were considered endorsement of the health condition. Obesity was determined from body mass index calculated from self-reported height and weight. Body mass index $\geq 30 \mathrm{~kg} / \mathrm{m}^{2}$ was considered obese.

Risk Factors We assessed tobacco use with the question, "How often do you currently use tobacco products (i.e. smoking, dipping, etc.)?" Participants were considered to use tobacco if they responded "Daily", "Several times a week", "Only occasionally", or "Monthly"; those who responded "I don't use tobacco products" were coded as nonusers. We determined physical activity level by asking "How many days a week do you usually do at least 30 minutes of physical activity or walking that increases your heart rate or makes you breath harder than normal? (e.g. mowing the lawn, carrying light loads, bicycling at a regular pace, jogging, etc.)". Low physical activity was defined as $<5$ days a week, since 5 or more days a week would be at least 150 min per week ( $30 \mathrm{~min} \times 5$ days) of physical activity, which is the national recommendation [17]. Fruit and vegetable intake was measured separately and was determined by asking two separate questions: "About how many servings of [fruit/vegetable] (include $100 \%$ pure [fruit/vegetable] juice) do you eat or drink each day?" Several examples for serving size were provided, and participants who responded $<2$ servings or $<3$ servings were defined as low fruit or low vegetable intake, respectively [18].

Demographic Characteristics We determined age by asking "How old are you?" and categorized responses as 18-24, 2544, 45-64, and 65+ years. Education was assessed with the question "What is the highest level of education you have completed?" For employment, we asked "Which of the following best describes your current, main daily activities and/ or responsibilities?" Household income was assessed by asking "What was the total combined income of your household in the past year, including income from all sources, such as wages, salaries, Social Security or retirement benefits, help from relatives and so forth? Please choose total income before taxes."

Statistical Analysis We used logistic regression and marginal standardization to calculate adjusted prevalence estimates for health outcomes and risk factors [19]. Models were adjusted for age, sex, marital status, education, employment, and study site (i.e., Nation A and Nation B). We did not include income as an adjustment variable due to missing data. The same method was used to calculate prevalence ratios and 95\% confidence intervals to examine the association between CVDrelated risk factors and health outcomes. Analyses were performed from July through August 2015 using Stata 12 (StataCorp LP, College Station TX, 2014).

\section{Results}

Nearly half of participants were aged 25-44 (46\%), while another third were aged $45-64$ years $(35 \%)$ (Table 1). The majority of participants were female (75\%), married or living with a partner $(60 \%)$, and had completed at least some postsecondary education (64\%). Most participants were employed (77\%), and 57\% had an average annual household income below $\$ 40,000$. Demographic characteristics were similar in both sites.

Adjusted prevalences for CVD-related health outcomes and risk factors are presented in Table 2. The overall prevalence of diabetes (25\%), obesity (56\%), and hypertension $(48 \%)$ was high. All three health outcomes were more prevalent among participants who were older, not currently married or living with a partner, had less education, and not employed. The prevalence of diabetes and obesity was similar in males and females, while the prevalence of hypertension was higher in males than females ( 58 vs. $45 \%$ ). The prevalence of obesity was higher in Nation A compared to Nation B (58 vs. 53\%), but the prevalence of diabetes and hypertension was similar in both study sites.

The prevalence of tobacco use was 26\% (Table 2). Tobacco use was the highest among participants aged 25-44 years (31\%), males (34\%), and those who had a high school education or less (34-39\%). The majority of participants reported low physical activity (71\%). Low physical activity was the most prevalent among participants aged 65 years and greater (81\%), females (77\%), and Nation A participants (78\%). The overall prevalence of low fruit intake was $56 \%$. Low fruit intake was more likely among the youngest participants aged 18-24 years (62\%) and Nation A participants (64\%). Three quarters $(75 \%)$ of participants reported low vegetable intake. Low vegetable intake was the highest among those who were not employed (82\%) and Nation A participants (80\%).

The prevalence of diabetes, obesity, and hypertension tended to be higher among participants who reported any tobacco use compared to those who did not, but these findings were not statistically significant (Table 3 ). The prevalences of these health outcomes were higher among participants with low physical activity levels compared to recommended physical activity levels. This was particularly evident for diabetes (PR 2.1, 95\% CI 1.4-3.2, $p=0.01$ ) and obesity (PR 1.5, 95\% 
Table 1 Demographic characteristics among American Indians from two tribal communities in Oklahoma

\begin{tabular}{llll}
\hline Characteristic & All participants & Nation A & Nation B \\
& $(n=513)$ & $(n=259)$ & $(n=254)$ \\
& $\%$ & $\%$ & $\%$ \\
\hline
\end{tabular}

\begin{tabular}{|c|c|c|c|}
\hline \multicolumn{4}{|l|}{ Age, years } \\
\hline $18-24$ & 9 & 9 & 10 \\
\hline $25-44$ & 46 & 48 & 44 \\
\hline $45-64$ & 35 & 33 & 37 \\
\hline $65+$ & 10 & 11 & 9 \\
\hline Female & 75 & 76 & 74 \\
\hline Married or living with partner & 60 & 63 & 57 \\
\hline \multicolumn{4}{|l|}{ Completed education } \\
\hline$<$ High school graduate & 6 & 5 & 7 \\
\hline High school graduate/GED & 30 & 34 & 26 \\
\hline Some college or some technical school & 30 & 27 & 33 \\
\hline $\begin{array}{l}\text { Associate's degree or technical college } \\
\text { degree }\end{array}$ & 21 & 24 & 17 \\
\hline 4-year college degree or higher & 14 & 10 & 17 \\
\hline Employed full- or part-time & 77 & 74 & 80 \\
\hline \multicolumn{4}{|l|}{ Household income in the past year } \\
\hline$<\$ 20,000$ & 26 & 27 & 26 \\
\hline$\$ 20,000-39,999$ & 31 & 32 & 30 \\
\hline$\$ 40,000-79,999$ & 27 & 24 & 30 \\
\hline$\$ 80,000+$ & 16 & 17 & 14 \\
\hline
\end{tabular}

Number of missing values: age $n=25$, marital status $n=4$, education $n=2$, employment $n=2$, income $n=4$
CI $1.2-1.8, p<0.01)$. We found little association between low fruit and low vegetable intake and the health outcomes.

\section{Discussion}

We found high rates of diabetes, obesity, and hypertension within both tribal nations as well CVD-related risk factors (i.e., tobacco use, low physical activity, and low vegetable and/or fruit intake). Our findings are consistent with the previous studies that showed that the prevalence of diabetes, obesity, and hypertension is higher among AIs than other racial/ ethnic groups [1, 20-22]. For instance, a recent analysis of National Health Interview Survey data found that, between 2004 and 2008, 39.4\% of AIs were obese compared with $24.3 \%$ of non-Hispanic whites, and $17.5 \%$ of AIs were diabetic compared to $6.6 \%$ of non-Hispanic whites [20]. Similarly, studies examining national BRFSS data, including our own analysis, have identified higher rates of obesity and diabetes for AIs (31 and 12.4\%) compared to respondents from all other racial/ethnic groups (20.9 and 6\%), and that these rates have steadily increased over the last two decades even as diabetes rates among non-Hispanic whites have remained relatively stable $[1,21,22]$. Data from the Oklahoma BRFSS reported that the prevalence of obesity and diabetes among Oklahoma AIs was even higher (42 and
$15 \%)$, while our current findings suggest that the prevalence of obesity (56\%) and diabetes (25\%) may be higher still in the most rural of tribal communities in Oklahoma.

The prevalence of hypertension in our study was $48 \%$. The Centers for Disease Control and Prevention (CDC) and Racial and Ethnic Approaches to Community Health (REACH 2010) initiative, which included a random cross-sectional survey of communities participating in REACH, showed that AIs had a higher prevalence of obesity (37.7\%), diabetes (19.7\%), and hypertension (36.8\%) compared to any other racial/ethnic group [23]. Further, AI adults were found to have the highest prevalence of these combined risk factors for CVD, with $>80 \%$ having one or more ( $88.2 \%$ men, $82.8 \%$ women) and over a third with three or more (35.7\% men, 33.3\% women) [23].

In our current study, AIs reported very low fruit and vegetable intake. These findings are consistent with the Strong Heart Study, and others reported that the diet in many AI communities is low in fruits and vegetables, high in fat, and below the Recommended Dietary Allowances for several vitamins and minerals, including calcium and iron [24, 25]. Surprisingly, we found no association between fruit and vegetable consumption and the selected health outcomes. One possible reason for this could be limitations of the twoquestion short assessment we administered. While we sought to administer a measure that limited respondent burden, a more comprehensive dietary measure may have yielded 
Table 2 Adjusted prevalence of health outcomes and cardiovascular disease risk factors among American Indians from two tribal communities in Oklahoma $(n=513)$

\begin{tabular}{|c|c|c|c|c|c|c|c|c|c|c|c|c|c|c|}
\hline & \multicolumn{6}{|c|}{ Health outcomes } & & & \multicolumn{6}{|c|}{ Risk factors } \\
\hline & \multicolumn{2}{|c|}{ Diabetes } & \multicolumn{2}{|c|}{ Obesity } & \multicolumn{2}{|c|}{ Hypertension } & \multicolumn{2}{|c|}{ Tobacco use } & \multicolumn{2}{|c|}{$\begin{array}{l}\text { Low physical } \\
\text { activity }^{\mathrm{a}}\end{array}$} & \multicolumn{2}{|c|}{$\begin{array}{l}\text { Low fruit } \\
\text { intake }\end{array}$} & \multicolumn{2}{|c|}{$\begin{array}{l}\text { Low vegetable } \\
\text { intake }^{c}\end{array}$} \\
\hline & $\%$ & $95 \% \mathrm{CI}$ & $\%$ & $95 \% \mathrm{CI}$ & $\%$ & $95 \% \mathrm{CI}$ & $\%$ & $95 \% \mathrm{CI}$ & $\%$ & $95 \% \mathrm{CI}$ & $\%$ & $95 \% \mathrm{CI}$ & $\%$ & $95 \% \mathrm{CI}$ \\
\hline Overall & 25 & $21-28$ & 56 & $51-60$ & 48 & $44-52$ & 26 & $22-29$ & 71 & $67-75$ & 56 & $51-60$ & 75 & $71-79$ \\
\hline \multicolumn{15}{|l|}{ Age, years } \\
\hline $18-24$ & 2 & $0-6$ & 21 & $9-33$ & 8 & $1-16$ & 24 & $12-36$ & 68 & $55-82$ & 62 & $48-77$ & 79 & $67-90$ \\
\hline $25-44$ & 14 & $9-19$ & 61 & $54-67$ & 37 & $30-43$ & 31 & $25-38$ & 74 & $68-80$ & 55 & $48-62$ & 79 & $73-84$ \\
\hline $45-64$ & 39 & $32-47$ & 60 & $52-67$ & 66 & $59-74$ & 25 & $19-32$ & 66 & $59-73$ & 58 & $51-66$ & 73 & $66-79$ \\
\hline $65+$ & 38 & $23-52$ & 50 & $34-65$ & 79 & $66-93$ & 8 & $7-15$ & 81 & $70-91$ & 42 & $27-57$ & 60 & $45-76$ \\
\hline \multicolumn{15}{|l|}{ Sex } \\
\hline Female & 25 & $21-29$ & 56 & $51-61$ & 45 & $40-50$ & 23 & $19-27$ & 77 & $73-82$ & 56 & $51-61$ & 74 & $69-78$ \\
\hline Male & 24 & $17-32$ & 53 & $44-62$ & 58 & $50-66$ & 34 & $25-42$ & 53 & $45-62$ & 55 & $46-64$ & 79 & $71-86$ \\
\hline \multicolumn{15}{|l|}{ Marital status } \\
\hline Never married, div/sep/wid & 29 & $23-35$ & 62 & $55-68$ & 52 & $45-58$ & 25 & $19-31$ & 68 & $62-74$ & 52 & $45-59$ & 70 & $64-77$ \\
\hline Married or living with partner & 21 & $17-26$ & 52 & $46-57$ & 46 & $41-51$ & 26 & $21-31$ & 74 & $69-79$ & 58 & $52-64$ & 78 & $73-83$ \\
\hline \multicolumn{15}{|l|}{ Completed education } \\
\hline$<$ High school graduate & 28 & $13-43$ & 57 & $38-76$ & 55 & $37-74$ & 39 & $20-58$ & 62 & $44-80$ & 55 & $36-74$ & 77 & $61-94$ \\
\hline High school graduate/GED & 28 & $21-35$ & 64 & $56-72$ & 56 & $48-63$ & 34 & $26-42$ & 69 & $61-76$ & 55 & $47-63$ & 78 & $71-85$ \\
\hline Some college or some technical school & 22 & $16-29$ & 54 & $46-62$ & 48 & $41-55$ & 30 & $23-37$ & 76 & $69-82$ & 60 & $52-68$ & 71 & $64-79$ \\
\hline Associate's or tech college degree & 21 & $13-29$ & 54 & $44-64$ & 43 & $34-52$ & 11 & $5-18$ & 76 & $67-84$ & 50 & $40-60$ & 74 & $65-83$ \\
\hline 4-year college degree or higher & 24 & $14-34$ & 43 & $31-55$ & 38 & $28-49$ & 12 & $4-20$ & 66 & $54-77$ & 55 & $43-68$ & 76 & $66-87$ \\
\hline \multicolumn{15}{|l|}{ Employment status } \\
\hline Not employed $^{\mathrm{d}}$ & 31 & $23-39$ & 64 & $55-74$ & 54 & $44-63$ & 31 & $22-40$ & 67 & $58-76$ & 55 & $46-65$ & 82 & $74-89$ \\
\hline Employed full- or part-time & 22 & $18-26$ & 53 & $48-58$ & 47 & $42-51$ & 24 & $20-28$ & 73 & $68-77$ & 56 & $50-61$ & 72 & $68-77$ \\
\hline \multicolumn{15}{|l|}{ Site } \\
\hline Nation A & 25 & $20-30$ & 58 & $52-64$ & 48 & $42-53$ & 25 & $20-31$ & 78 & $73-93$ & 64 & $58-70$ & 80 & $75-85$ \\
\hline Nation B & 24 & $19-29$ & 53 & $47-60$ & 49 & $43-55$ & 26 & $20-31$ & 64 & $58-71$ & 46 & $40-53$ & 70 & $64-76$ \\
\hline
\end{tabular}

Adjusted for age, sex, marital status, education, employment, and site

${ }^{a}<5$ days/week of at least 30 min of physical activity per day

${ }^{\mathrm{b}}<2$ servings/day

${ }^{c}<3$ servings/day

${ }^{\mathrm{d}}$ Unemployed, student, homemaker, disabled, and retired

different results. Additionally, evidence suggests that incorporating elements of cultural and racial food preferences as well as geographic region may further refine standard dietary measurements to be more accurate in diverse populations [26].

Additionally, $71 \%$ of participants in our study reported low physical activity, consistent with other studies that have reported that most AI adults, and more than three quarters of AI youth, do not meet minimum public health recommendations for physical activity [27, 28], even though some evidence suggests that AIs engage in physical activity at higher rates than other racial/ethnic groups [29]. Finally, $25 \%$ of individuals we surveyed reported using tobacco. Data from the 2014 National Health Interview Survey reported that $29.2 \%$ of AIs smoked, nearly double the rate found in the US general population (16.8\%), and the highest of any racial/ethnic group [30].

Findings from our study support existing literature that CVD-related health disparities persist among AIs despite the implementation of universal policy approaches, such as smoking bans or comprehensive health care reform via the Affordable Care Act [10]. For example, between 2005 and 2014, smoking rates declined within the US general population by nearly $20 \%$, while the reduction among AIs was less than $8 \%$ [30]. The National Healthcare Disparity Annual Report, issued by the Agency for Healthcare Research and Quality, found that in 2015, AIs had worse access to care than whites for $30 \%$ of access measures and received worse care than whites for about $40 \%$ of quality measures [31]. The 
Table 3 Adjusted association between cardiovascular disease risk factors and health outcomes among American Indians from two tribal communities in Oklahoma

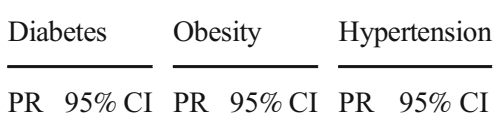

Use of any tobacco products $\quad 1.2 \quad 0.8-1.7 \quad 1.0 \quad 0.9-1.2 \quad 1.1 \quad 0.9-1.4$

$\begin{array}{llllllll}\text { Low physical activity }^{\mathrm{a}} \quad & 2.1 & 1.4-3.2 & 1.5 & 1.2-1.8 & 1.1 & 0.9-1.3\end{array}$

$\begin{array}{lllllll}\text { Low fruit intake }^{\mathrm{b}} & 1.2 & 0.9-1.6 & 1.1 & 0.9-1.3 & 1.0 & 0.8-1.1\end{array}$

$\begin{array}{llllllll}\text { Low vegetable intake }^{c} & 1.0 & 0.7-1.4 & 1.1 & 0.9-1.3 & 0.9 & 0.7-1.0\end{array}$

Adjusted for age, sex, marital status, education, employment, and site

$P R$ prevalence ratio

${ }^{\text {a }}<5$ days/week of at least 30 min of physical activity per day

${ }^{\mathrm{b}}<2$ servings/day

${ }^{c}<3$ servings/day

report also found that disparities are not narrowing with improvements in health care [31].

Indeed, efforts to make meaningful progress in eliminating AI health disparities must address several key issues. First, AIs must be regularly included in national health surveys. The exclusion of AIs due to small sample sizes hinders efforts to monitor AI health status and identify important geographic and sociodemographic differences in health outcomes that exist within and across this diverse population [1, 11, 12]. Regular tracking of AI health behaviors and risk factors will support tribal leaders to make informed policy decisions to address and eliminate disparities.

Additionally, despite the widespread promotion of health enhancing environmental and policy interventions (e.g., menu labels, bike lanes, food pricing), their generalizability to tribal communities and settings remains unclear [32-35]. Tribal policymaking processes often remain poorly understood by researchers and health planners alike, hindering the evaluation and scale-up of effective health promotion interventions and widening disparities. Research efforts on state and national health promotion policies and determinants of policy adoption must include tribal policies within their analyses. Finally, efforts to intervene upon the "root causes" of AI health disparities_-poor housing, unemployment, and limited or no access to healthy foods - via multilevel interventions that address the social and political contexts creating and maintaining AI health inequities must be prioritized.

To that end, findings from this survey, as well as other data collected as part of this study, were presented back to community members and tribal leaders to develop environmental interventions to address CVD and diabetes. Interventions to improve both the food and physical activity environments were identified. Ultimately, the tribal food environments, specifically tribally owned and operated convenience stores, were prioritized. We selected these environments within which to intervene because the tribes had full authority in these settings to make environmental and policy changes. We also sought to capitalize on the growing momentum within both nations, identified through 12 focus groups we conducted, for greater community access to healthy and affordable foods. Therefore, we randomized eight tribally owned convenience stores (four controls and four interventions) and implemented "healthy makeovers" within the stores consisting of: (1) increased availability and convenience of healthy foods, (2) reduced pricing for healthy foods, and (3) the promotion and marketing of these foods within the tribal stores. The intervention and its trial, now underway, are part of a new "Health in All Policymaking" approach initiated by both nations. With the ultimate aim of disseminating findings and lessons learned to tribal policymakers within and beyond Oklahoma, our tribalacademic partnership is using best practice recommendations for the synchronous implementation and research, "learning and doing," and assessing the health impact and costeffectiveness of our intervention strategies. In doing so, we hope to facilitate the future scale-up of promising practices that will lead to sustained improvements in the risk factors and health outcomes examined in the current study as well as others critical to the health and well-being of American Indian communities.

\section{Limitations}

This study has several limitations. Although efforts were made to select a diverse sample of AIs across the two tribal nations, this was not a random sample. Thus, our findings are limited in their generalizability even within the tribal nations in which they were collected. Similarly, our sample was overwhelmingly female. Due to missing data, we were not able to control for income. We instead included employment and education in our adjusted models. Additionally, while we examined a comprehensive set of risk factors and health outcomes, all data were self-reported and may not be accurate assessments of health behavior or health status. We do, however, present prevalences and adjusted ORs from multiple logistic regression models that controlled for confounding factors, and the findings of our study are consistent with those of other studies examining CVD-related health outcomes among AIs. Further, our study contributes to the gap in existing literature regarding CVD-related health outcomes.

\section{Conclusion}

The AI population is regularly excluded from national health surveys due to small sample sizes.

Research to address CVD-related disparities among AIs is seriously hampered by researchers' and health planners' unfamiliarity with the tribal policymaking process and the absence of tested strategies to engage tribal leaders the 
development of policy and environmental interventions. As a result, the feasibility of implementing evidence-based policy and environmental interventions to address such disparities has not been adequately examined within the diverse sociocultural and political contexts of sovereign tribal nations. Multilevel interventions that address the social determinants of these and other disparities as well as the development of strategies for the scale-up and implementation of interventions shown to be effective within AI communities are critical to the elimination of persistent AI health disparities.

\section{Compliance with Ethical Standards}

Conflict of Interest The authors declare that they have no conflict of interest..

Funding This study was funded by the National Heart, Lung, and Blood Institute (Grant no. HL117729).

Ethical Approval (Animals) This article does not contain any studies with animals performed by any of the authors.

Ethical Approval (Human Subjects) All procedures performed in studies involving human participants were in accordance with the ethical standards of the institutional and/or national research committee and with the 1964 Helsinki Declaration and its later amendments or comparable ethical standards.

This study was reviewed and approved by the Institutional Review Boards of the University of Oklahoma as well as the Chickasaw Nation and Choctaw Nation of Oklahoma. Per the preferences of the tribal partners tribal identity are not included when presenting specific survey results.

Informed Consent Informed consent was obtained from all individual participants included in the study.

Open Access This article is distributed under the terms of the Creative Commons Attribution 4.0 International License (http:// creativecommons.org/licenses/by/4.0/), which permits unrestricted use, distribution, and reproduction in any medium, provided you give appropriate credit to the original author(s) and the source, provide a link to the Creative Commons license, and indicate if changes were made.

\section{References}

1. Jernigan VBB et al. Changing patterns in health behaviors and risk factors related to cardiovascular disease among American Indians and Alaska Natives. Am J Public Health. 2010;100(4):677-83.

2. United Health Foundation. America's Health Rankings. 2015. http://cdnfiles.americashealthrankings.org/SiteFiles/Reports/2015 AHR Annual-v1.pdf. Accessed 17 Nov 2016.

3. Centers for Disease Control and Prevention. Behavioral Risk Factor Surveillance System Survey Questionnaire. 2013. https://www.cdc. gov/brfss/questionnaires/pdf-ques/2014_brfss.pdf. Accessed 18 Nov 2016

4. Polley DC et al. Intrafamilial correlates of overweight and obesity in African-American and Native-American grandparents, parents, and children in rural Oklahoma. J Am Diet Assoc. 2005;105(2): 262-5.

5. Hearst MO et al. The co-occurrence of obesity, elevated blood pressure, and acanthosis nigricans among American Indian school children: identifying individual heritage and environment-level correlates. Am J Hum Biol. 2011;23(3):346-52.

6. Neumark-Sztainer D et al. Ethnic/racial differences in weightrelated concerns and behaviors among adolescent girls and boys: findings from Project EAT. J Psychosom Res. 2002;53(5):963-74.

7. Seligman HK, Laraia BA, Kushel MB. Food insecurity is associated with chronic disease among low-income NHANES participants. J Nutr. 2010;140(2):304-10.

8. Kaufman P, Dicken C, Williams R. Measuring access to healthful, affordable food in American Indian and Alaska Native Tribal areas. US Department of Agriculture Economic Research Service Economic Information Bulletin. 2014 Dec(131). http://www.ers. usda.gov/publications/pub-details/?pubid $=43908$. Accessed 18 Nov 2016.

9. Oklahoma State Department of Health. Behavioral Risk Factors Among American Indians in Oklahoma: Report on the REACH 2010 Native American Behavioral Risk Factor Survey and the Non-Phone Behavioral Risk Factor Survey. 2004. https://www.ok. gov/health2/documents/HCI BRFSSNativeAmerican2004.pdf. Accessed 18 Nov 2016.

10. Warne D, Frizzell LB. American Indian health policy: historical trends and contemporary issues. Am J Public Health. 2014;104(S3):S263-7.

11. Galloway JM. Cardiovascular health among American Indians and Alaska Natives: successes, challenges, and potentials. Am J Prev Med. 2005;29(5):11-7.

12. Bauer UE, Plescia M. Addressing disparities in the health of American Indian and Alaska Native people: the importance of improved public health data. AM J Publi Health. 2014;104(S3):S255-7.

13. Dreisinger M. Patterns of childhood obesity prevention legislation in the United States. Transportation. 2007;11:13.

14. Boehmer TK et al. Preventing childhood obesity through state policy: predictors of bill enactment. Am J Prev Med. 2008;34(4):333-40.

15. Jernigan VBB, Jacob T, Styne D. The adaptation and implementation of a community-based participatory research curriculum to build tribal research capacity. Am J Public Health. 2015;105(S3): S424-32.

16. Norris, T, Vines, PL, and Hoeffel, EM. US Bureau of the Census. The American Indian and Alaska Native Population: 2010. 2010 Census Briefs. January 2012. http://www.census.gov/prod/cen2010 /briefs/c2010br-10.pdf. Accessed 18 Nov 2016.

17. US Department of Health and Human Services, Office of Disease Prevention and Health Promotion. Physical activity guidelines for Americans. October 2008 . https://health. gov/paguidelines/pdf/paguide.pdf. Accessed 18 Nov 2016.

18. Thompson FE et al. Fruit and vegetable assessment: performance of 2 new short instruments and a food frequency questionnaire. J Am Diet Assoc. 2002;102(12):1764-72.

19. Muller CJ, MacLehose RF. Estimating predicted probabilities from logistic regression: different methods correspond to different target populations. Int J Epidemiol. 2014;43(3):962-70.

20. Barnes, PM, Powell-Griner, E, and Adams, PF. National Center for Health Statistics. Health characteristics of the American Indian and Alaska Native Adult population, United States, 1999-2003. 2005. https://www.cdc.gov/nchs/data/ad/ad356.pdf. Accessed 18 Nov 2016.

21. Denny CH, Holtzman D, Cobb N. Surveillance for health behaviors of American Indians and Alaska Natives. Findings from the Behavioral Risk Factor Surveillance System, 1997-2000. MMWR Surveill Summ. 2003;52(7):1-13. 
22. Steele $\mathrm{CB}$ et al. Surveillance for health behaviors of American Indians and Alaska Natives - findings from the Behavioral Risk Factor Surveillance System, 2000-2006. Cancer. 2008;113(S5):1131-41.

23. Centers for Disease Control and Prevention. Health status of American Indians compared with other racial/ethnic minority population - selected states, 2001-2002. MMWR Morb Mortal Wkly Rep. 2003;52(47):1148-52.

24. Welty TK et al. Changes in cardiovascular disease risk factors among American Indians: the Strong Heart Study. Ann Epidemiol. 2002;12(2):97-106.

25. Story $\mathrm{M}$ et al. Obesity in American-Indian children: prevalence, consequences, and prevention. Prev Med. 2003;37:S3-S12.

26. Signorello LB, Munro HM, Buchowski MS, et al. Estimating nutrient intake from a food frequency questionnaire: incorporating the elements of race and geographic region. Am J Epidemio. 2009;170(1):104-11.

27. Dennison M, Sisson S, Lora K, et al. J Community Health. 2015;40(4):808-14.

28. Foulds H, Warburton D, Bredin S. A systematic review of physical activity levels in Native American populations in Canada and the United States in the last 50 years. Obes Rev. 2013;14:593-603. doi:10.1111/obr.12032.
29. Kim M, Larson J. Health disparities and exercise among ethnic groups. J Intercultural Disciplines. 2013;11:41-50.

30. Jamal A et al. Current cigarette smoking among adults - United States, 2005-2014. MMWR. 2015;64(44):1233-40.

31. US Department of Health and Human Services. Quality and disparities in quality of health care. Rockville: Agency for Healthcare Research and Quality; 2016.

32. Blue Bird Jernigan V, Boe G, Noonan C, Carroll L, Buchwald D. Assessing community readiness to implement obesity prevention policies in two American Indian reservations. J Health Dispar Res Pract. 2016 Fall;9(3):168-80.

33. Blue Bird Jernigan $\mathrm{V}$ et al. The implementation of a participatory manuscript development process with Native American tribal awardees as part of the CDC Communities Putting Prevention to Work initiative: challenges and opportunities. Prev Med. 2014;67(Supplement 1):S51-7.

34. Blue Bird Jernigan V et al. Addressing food insecurity in a Native American reservation using community-based participatory research. Health Educ Res. 2012;27(4):645-55.

35. Fleischhacker $\mathrm{S}$ et al. Tools for healthy tribes: improving access to healthy foods in Indian country. Am J Prev Med. 2012;43(3): S123-9. 